\title{
Is Aggressive Trait Responsible for Violence? Priming Effects of Aggressive Words and Violent Movies
}

\author{
Zhang Qian ${ }^{1,2,3}$, Dajun Zhang ${ }^{1,2,4^{*}}$, Lixin Wang ${ }^{1,2,4}$ \\ ${ }^{1}$ Center for Mental Health Education, Southwest University, Chongqing, China \\ ${ }^{2}$ Department of Psychology, Southwest University, Chongqing, China \\ ${ }^{3}$ School of Applied Technology, Southwest University, Chongqing, China \\ ${ }^{4}$ Key Laboratory of Cognition and Personality, Ministry of Education (SWU), Chongqing, China \\ Email: zhangdj@swu.edu.cn, zhq@swu.edu.cn
}

Received November $15^{\text {th }}, 2012$; revised December $17^{\text {th }}, 2012$; accepted January $10^{\text {th }}, 2013$

\begin{abstract}
The aim of the present study was to examine the priming effects of violent movies and aggressive words on implicit aggression by using modified STROOP task. 190 adolescents participated in this study, with 95 assigned to non-violent movie group and 95 assigned to violent movie group. The results showed that no significant difference was found in the main affect of Movie Type, but it revealed significant Movie Type $\times$ Aggressive Trait interaction, and that aggression was significantly influenced by violent movie only for high-aggressive trait (HT) adolescents, but not for mid-aggressive trait (MT) and low-aggressive trait (LT) adolescents. The possible underlying mechanism was that HT adolescents may possess a relatively stronger aggressive network of cognitive association which was easily activated by violence than MT and LT adolescents. This indicated that violent movie could effectively elicit implicit aggression for adolescents who were highly aggressive, but not for nonaggressive adolescents.
\end{abstract}

Keywords: Aggressive Trait; Violence; Aggressive Words; Violent Movies; Adolescents; STROOP Task

\section{Introduction}

Aggression was a kind of cognition, affect and behavior directed toward another individual that was carried out with the intent to cause harm (Anderson \& Bushman, 2002). Besides, the perpetrator must assure that the attacking behavior would harm the target, and that the target was motivated to avoid the behavior (Bushman \& Anderson, 2001; Baron \& Richardson, 1994; Berkowitz, 1993; Geen, 2001). In other words, accidental hurt was not an aggressive behavior because it was not intentional. Harm which was only a by-product of pro-social behavior could not be defined as aggression, for the target is not motivated to avoid the action (e.g. pain experienced during an operation in hospital). The study discussed the type of implicit aggression, which was elicited by violent stimuli in cognitive processing.

With China entering into the era of information technology (IT), numerous kids had more and more opportunities to watch violent movies online, and they were prone to imitate aggressive behavior from the developmental perspective. Furthermore, China was also undergoing social transition and transformation, which greatly accelerated the speed of obtaining media violence for adolescents. As a result, some adolescents, who lacked basic values and moral judgments, were easily influenced by violent movies (e.g. high-aggressive trait, aggressive behavior).

Currently, a vast majority of prior literatures reported that media violence increased aggressive behavior, whereas other experts were still suspicious about this conclusion. It seemed that a long-term debate was existed with regard to this issue. Some researchers assumed that television violence promotes aggressiveness (Berkowitz, Corwin, \& Heironimus, 1963; Black

\footnotetext{
*Corresponding author.
}

\& Bevan, 1992; Centerwall, 1989; Hennigan et al., 1982; Williams, 1986; Messner, 1986; Leyens et al., 1975). In particular, experts claimed violent movies result in anti-social behavior, strongly supporting the causal hypothesis of film violence and aggression through meta-analysis (Paik \& Comstock, 1994). Other experts suggested that exposure to media violence is a causal factor for increased aggressive behavior, cognition, and affect and for decreased empathy and pro-social behavior (Anderson, 2010). Additionally, rewarding violent game actions increased hostile emotion, aggressive thinking and behavior. Punishing violent actions increased hostile emotion, but did not increase aggressive thinking and behavior (Carnagey \& Anderson, 2005; Ballard \& Rober, 1999). The more time playing violent media equaled more aggression (Bègue, Scharkow, \& Bushman, 2013). Other scholars, on the contrary, argued that the evidence above was not overwhelming, and it provided no reason to believe media violence causes aggression. For example, Freedman $(1984,1986)$ admitted positive correlation exists, but denied that media violence surely causes aggression. Moreover, it was concluded that either no effect of violent television has on aggression, or it is vanishingly small (Freedman, 2002, 2004; Anderson \& Carnagey, 2009). Based on these views, it seemed that there was still a close connection between violent movie and aggression (Anderson, 1997; Paul \& Adachi, 2011; Anderson, \& Nicholas, 2009; Gentile et al., 2004; Berkowitz, Corwin., \& Heironimus, 1963; Centerwall, 1989; Dubanoski \& Parton, 1971; Huesmann, 1986; Huesmann et al., 2003). Overall, most research indicated positive correlation exists between media violence and aggression across methodologies, crosscultures, and media types (TV, video game, movie).

Despite violent media was an important factor leading to aggressiveness, which was not the only factor (Bushman \& Ander- 
son, 2001). At present, researchers began to explore the moderating role of some variables (e.g. trait aggressiveness; arousal, content, gender, etc.) in the effects of violent media on aggression, and significant positive correlation was found between media violence and aggression. For instance, Bushman (1995) found media violence was more likely to increase aggression in high trait aggressive individuals than in low aggressive individuals. This may imply a causal correlation between aggression and aggressive traits.

As to research paradigm, prior researches used STROOP task to make subjects identify the color of aggressive or nonaggressive word instead of word meaning, so as to figure out the cognitive processes. If subjects showed characteristics of delay when naming the word color, explaining that they may consume lots of attentional and cognitive resources. For example, Smith \& Waterman (2005) explored sex differences in processing words related to directly and indirectly aggressive act by using STROOP task. Anderson et al. (1998) used a modified STROOP task to investigate significant effects of the weapon versus non-weapon primes on reaction time to aggression. In particular, Anderson et al. (1996) used STROOP interference task to assess hostile cognition, and stimulus words (aggressive words, control words and escape words), which were presented in one of five colors (red, green, blue, yellow and white). What's more, a recent brain research demonstrated the importance of fronto-limbic structures for cognitive processing, suggesting that media violence may affect individuals in different ways depending on aggressive traits (Kalnin et al., 2011; Bertsch et al., 2009).

In this study, we examined whether significantly priming effects of violent movies and aggressive words were found in violent and non-violent movie groups. Hence, the study explored whether aggressive words could provoke adolescents' aggression by watching violent or nonviolent movies, and further investigated how implicit aggression was elicited by aggressive trait. In this study, two hypotheses were proposed.

1) Hypothesis 1. Violent movies may effectively provoke adolescents' aggression.

2) Hypothesis 2. HT adolescents may demonstrate higher aggression than MT and LT adolescents by watching violent movies.

\section{Method}

\section{Procedure and Participants}

All participants were asked to complete Buss-Perry Aggression Questionnaire (BPAQ), and then they were about to participate in the modified STROOP task. The data were gathered in four classes of approximately 48 participants each. After achieving informed consent, participants were randomly distributed to watch violent or nonviolent movie clips and given 30 minutes to complete the paper-and-pencil questionnaire. Then they finished STROOP task on computer. The modified STROOP task was programmed by E-prime software, and instructions were presented on screen: "The task is to test your speed and accuracy of responses, and the goal words will be presented in different color. If the word color is green, press 1 on keyboard, if the word color is blue, press 2. You should react as quickly and accurately as possible to determine the word color instead of meaning, then the next trial begins." After instructions appeared, a gray sign "+" emerged on the screen centre with the time of $300 \mathrm{~ms}$, and the stimulus words lasted for $1500 \mathrm{~ms}$. If participants did not respond in $1500 \mathrm{~ms}$, the program would automatically enter into the blank screen of next trial for $100 \mathrm{~ms}$. The inter-stimulus-interval (ISI) was 200 to $300 \mathrm{~ms}$. Meanwhile, accuracy rate and reaction time (RT) were recorded (See Figure 1). The whole experiment was divided into two sessions: 1) Practical session. The session was to familiar participants with experimental procedure, especially for the counterbalance between color and key pressing. 30 trials were existed but did not appear in formal session. The program returned to practical session if the accuracy rate was below 80 percent. 2) Formal session. It was divided into 3 blocks, in which 60 trials and totally 180 trials were presented. Both 30 aggressive and 30 nonaggressive words were presented in one of two colors (blue, green), and the same word did not appear repeatedly in each block. Participants should focus their attention to the screen centre, and they could have a short rest among blocks. After the experiment, participants (especially HT adolescents) were debriefed about their aggressive affect, cognition, and attitude, in order to know their implicit aggression to violence. All participants were treated according to the ethical guidelines of the American Psychological Association (APA, 2001).

The total participants were 190 adolescents ( 95 boys, 95 girls) from a small high school in the southwestern area of China. Adolescents ranged in age from 15 to 19 years $(M=16.22, S D$ $=1.21$ ). $71 \%$ were from urban area while $29 \%$ were from countryside area. Approximately $88 \%$ were Han majority, while $9 \%$ were Tujia minority, $3 \%$ were Miao minority. These demographics represent the student population at this school. 95 adolescents watching THE BIG FAT KILL were regarded as violent movie group, and 95 adolescents viewing LITTLE BASCALS were deemed as nonviolent movie group (See Table 1).

\section{Experimental Design}

Multi-factorial design was used, with Movie Type and Aggressive Trait as independent variables and Aggression as dependent variable. 2 (Movie Type: violent vs. non-violent) $\times 2$ (Goal Word: aggressive vs. non-aggressive) $\times 3$ (Aggressive Trait: HT, MT, LT) repeated three measures analysis of variance (ANOVA) was conducted with Movie Type and Aggressive Trait as between-group factor, and Goal Word as withingroup factor. According to score distribution, participants who got score at the top of $27 \%$ on Buss Perry Aggression Questionnaire (BPAQ) were defined as HT, and the last $27 \%$ were seen as LT, and the rest were considered as MT.

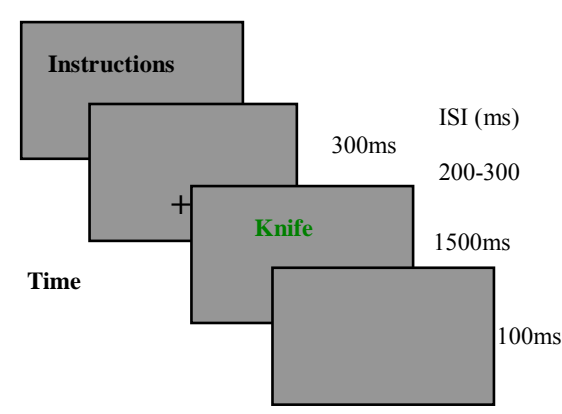

Figure 1.

Modified STROOP task procedure. 
Table 1.

Participants in the modified STROOP task.

\begin{tabular}{|c|c|c|c|c|}
\hline \multirow{2}{*}{ Group type } & \multicolumn{3}{|c|}{ Aggressive trait } & \multirow[t]{2}{*}{ Overal } \\
\hline & HT & MT & LT & \\
\hline Violent movie group & 31 & 29 & 35 & 95 \\
\hline Nonviolent movie group & 28 & 30 & 37 & 95 \\
\hline Overall & 59 & 59 & 72 & 190 \\
\hline
\end{tabular}

\section{Stimuli and Measures}

\section{Movie Clips}

SIN CITY (also known as Frank Miller's SIN CITY), was a 2005 American crime thriller film written, produced and directed by Frank Miller and Robert Rodriguez (Maitland, 2011). The plot of the file, THE BIG FAT KILL ${ }^{1}$, was selected as a violent movie clip in the study. LITTLE BASCALS (also known as OUR GANG), directed by Penelope Spheeris (Leonard \& Richard, 1977, 1992), was a series of 1994 American comedy short films and chosen as nonviolent movie clip in the study. The violent movie clip included body-fighting scenes between two males with language attack, whereas the nonviolent movie clip included no body-fighting content and language attack. The watching time of each movie clip lasted for 15 minutes.

\section{Computer}

The computer resolution rate was $1024 \times 576$, and the refresh rate was $60 \mathrm{~Hz}$. The distance between participants and screen was around $60 \mathrm{~cm}$, their faces and eyes were parallel with the screen.

\section{Goal Words}

30 aggressive and 30 nonaggressive words were randomly matched. The words were used in No. 48 black italics and presented in one of two colors (green, blue) with a gray background. The presented order was counterbalanced.

\section{Buss-Perry Aggression Questionnaire (BPAQ)}

$\mathrm{BPAQ}$, a 5-point rating scale, was used to measure aggressive trait (HT, MT, LT). BPAQ consists of four dimensions: physical aggression (PA), verbal aggression (VA), anger (A), and hostility $(\mathrm{H})$. Internal consistent reliability (Cronbach-alfa coefficient) for the Scale was .94. Test and re-test reliability yielded a correlation coefficient of .89. Cronbach-alfa coefficients of physical aggression, verbal aggression, anger, and hostility were $.85, .72, .83$ and .77 , respectively. The questionnaire supports the convergent validity as a measure of aggression (Buss \& Perry, 1992).

\section{Results}

\section{Priming Effects of Violent Movies and Aggressive Words on Aggression}

A repeated measures analysis of variance (ANOVA) was carried out to examine the main effect of goal words on implicit aggression. Table 2 showed that a significant main effect of

${ }^{1}$ THE BIG FAT KILL focused on a street war between a group of prostitutes and a group of mercenaries, the police, and the mob. LITTLE BASCALS told about a group of poor neighborhood children and the adventures they had together. The series was noted for showing children behaving in a relatively natural way. goal word was found in reaction time (RT), and the mean RT of aggressive words was significantly longer than that of nonaggressive words $(F=4.5677, p<.05)$.

\section{The Main Effect of Movie Type, Movie Type $\times$ Aggressive Trait Interaction}

In the study, we would like to verify the aggressively priming effect of violent movie and aggressive word on implicit aggression, and postulated each participant had a mean aggressively priming score (APS), which meant the calculated score for the mean RT value of aggressive words minus nonaggressive words for the violent movie group (THE BIG FAT KILL), and found whether significant difference of APS in group type (See Table 3).

Although the average APS of violent movie group $(11 \mathrm{~ms})$ was higher than that of non-violent movie $(-3 \mathrm{~ms})$ by watching violent movies (See Table 3), Table 4 showed no significant difference in main effect of movie type on aggression $(F=.79$, $p>.05)$.

Multivariate analysis of covariance (MANCOVA) was used to test whether significant difference was found in APS among independent variables (See Table 4).

As can be seen in Table 4, there was significant Movie Type $\times$ Aggressive Trait interaction $(F=6.45, p<.05)$. Further simple effect analysis showed the average APS of HT adolescents watching violent and non-violent movies were 16.78 and -2.95 , respectively, and that aggression of HT adolescents was significantly elicited by violent movie clips $(F=$ $9.81, p<.05)$. The average APS of MT adolescents viewing violent and non-violent movies were 11. 09 and 16.43, respectively, and that aggression of MT participants was not significantly elicited by violent movies $(F=2.84, p>.05)$. The average APS of LT participants watching violent and non-violent movies were -.66 and -2.82 , respectively, and that aggression of LT participants was not significantly elicited by violent movies $(F=.06, p>.05)($ See Table 5).

\section{Discussion}

The main purpose of the study was to explore the priming effect of violent movies and aggressive words on adolescents'

Table 2.

Differences between aggressive and nonaggressive words in RT.

\begin{tabular}{cccccc}
\hline \multicolumn{6}{c}{ Goal words } \\
\hline \multicolumn{7}{c}{ Aggressive words } & \multicolumn{1}{c}{ Non-aggressive words } & $F$ \\
$M$ & $S D$ & & $M$ & $S D$ & \\
\hline RT & 545 & 53.16 & 531 & 51.88 & $4.677^{*}$ \\
\hline
\end{tabular}

Note: ${ }^{*} p<.05 ;{ }^{* *} p<.01 ;{ }^{* * *} p<.001$.

Table 3.

Mean RT (ms) to aggressive and nonaggressive words between violent and nonviolent movie group.

\begin{tabular}{lccccc}
\hline \multicolumn{7}{c}{ Goal words } \\
\hline Group type & $M$ & $S D$ & $M$ & $S D$ & APS \\
\hline Violent movie group & 684 & 88.26 & 695 & 93.07 & +11 \\
Nonviolent movie group & 691 & 84.43 & 688 & 100.81 & -3 \\
Aggressively priming effect & & & & +14 \\
\hline
\end{tabular}

Note: Aggressively priming effect = mean aggressively priming score for violent movie group. 
Table 4.

MANCOVA in APS between movie type and aggressive trait.

\begin{tabular}{lrrl}
\hline Independent variables & $M$ & \multicolumn{1}{c}{$S D$} & $F$ \\
\hline Movie type & 238 & 23.66 & .79 \\
Movie type $\times$ Aggressive trait & 1727 & 285.49 & $6.45^{* *}$ \\
\hline
\end{tabular}

Note: ${ }^{*} p<.05 ;{ }^{* *} p<.01 ;{ }^{* * *} p<.001$.

Table 5.

Post Hoc in APS among aggressive traits by watching movie clips.

\begin{tabular}{lccc}
\hline Aggressive trait & Violent movie & Non-violent movie & $F$ \\
\hline High-aggressive & 16.78 & -2.95 & $9.81^{*}$ \\
Mid-aggressive & 11.09 & 16.43 & 2.84 \\
Low-aggressive & -.66 & -2.82 & .06 \\
\hline
\end{tabular}

Note: ${ }^{*} p<.05 ;{ }^{* *} p<.01 ;{ }^{* * *} p<.001$.

implicit aggression. Overall, there was no significant difference in main effect of movie type on aggression, but significant Movie Type $\times$ Aggressive Trait interaction was found, and that implicit aggression of HT was significantly elicited by violent movies. Nevertheless, the implicit aggression of adolescents with moderate and low aggressive trait was not significant elicited by aggressive words. This result was in consistent with previous researches (Bushman, 1995, 1996; Anderson, 1997; Cross \& Campbell, 2012; Khoury, 2012; Wallace et al., 2012). Therefore, we may infer that HT adolescents were more likely to choose violent movies than MT and LT adolescents in their daily life, and their aggression would be easily activated by violent stimuli.

In agreement with our hypothesis 1 , the study showed that violent movie effectively activated Chinese adolescents' implicit aggression. Both movie type and aggressive trait affected aggression, partly supporting General Aggressive Model (GAM) and Cognitive-new Association Model (CAM). It should be noticed that, however, implicit aggression of MT and LT adolescents was not significantly affected by violent movie, which partly testified hypothesis 2 . By what casual mechanisms did these priming effects occur? According to cognitive neoassociation theory (Bushman \& Geen, 1990; Berkowitz, 1984), high trait aggressive individuals were more susceptible to effects of violent movies than low-aggressive individuals because of the larger aggressive association network activated. Thus, HT adolescents may have stronger aggressively cognitive-association network than MT and LT adolescents, demonstrating significant implicit aggression. One characteristic of the study was that violent movies aroused implicit aggression for MT individuals, which previous research didn't examine. In light of this result, we inferred that repeated exposure to violent movies may form aggressively cognitive schema for HT adolescents, and easily caused aggression.

Compared with this study, undergraduate psychology students were used as main participants in previous research (Bushman, 1995). In the present study, Chinese adolescents were used as participants, and STROOP task was employed to investigate whether aggressive trait affects cognitive processing on aggressive words. Besides, previous studies showed the significant main effect of movie type, and that participants who viewed violent movies showed higher state of hostility than did those who watched nonviolent movies (Anderson, 1997). The study, however, demonstrated no significant main effect of movie type, and that no significant difference was found in implicit aggression activated between participants viewing vio- lent movie clips and those viewing nonviolent movie clips. Perhaps difference among these factors was averaged and offset, which led to this result. Moreover, introspective methods were used to let participants describe their aggressive feelings, which could make up for the experimental research fault.

\section{Limitation}

This study may be one of the first to explore priming effects of violent movies and aggressive words on implicit aggression of adolescents in China. Also this was one of the first to find the impact of aggressive traits (HT, MT, LT) on implicit aggression for Chinese adolescents. The results of this study, however, should be noticed in light of some limitations. First, the sample selected in the study was a relatively small and homogeneous group at a high school. As a result, cautions should be made when the conclusions were generalized to another population (e.g. cross-cultures, multi-nation). Second, the data we obtained from a cross-sectional design, which prevented the final determination of casual relationships. Third, in this study, all participants were asked to complete BPAQ, which was use to assess aggressive trait in the US Perhaps some items in the scale were not suitable for the reality of adolescents under Chinese traditionally cultural background. In future study, researchers should consider using a revised edition of BPAQ to survey and obtain data, to scientifically and exactly classify aggressive trait. Additionally, longitudinal studies should be developed to provide stronger evidence on the relationships among variables explored in the study. Last, emphasis should be placed on the case that watching violent movies surely led to aggression. We should draw conclusions with great caution and care. Upon this study, it just showed that violent movies and aggressive words may provoke implicit aggression only for HT adolescents, not on all adolescents who viewed violent movies. Presumably, this was the reason why so many prior researchers had fierce debates on this issue for a long period (Freedman, 2002).

\section{Conclusion}

In the present study, we have examined the priming effects of violent movie and aggressive words on implicit aggression of Chinese adolescents by employing STROOP word-color naming task. What' more, we concluded that aggressive words could elicit implicit aggression of HT adolescents rather than MT and LT adolescents. Thus, this result should not be interpreted to generalize that watching violent movies surely elicit all adolescents' implicit aggression.

\section{Acknowledgements}

The study was funded by the Scientific Research Grants of Southwest University (Grants Number: SWU1209504). Sincere thanks should be given to Dr. Jinliang Wang and Dr. Zhu Yi for their helpful suggestions on this manuscript.

\section{REFERENCES}

American Psychological Association (2001). Publication manual of the American Psychological Association (5th ed.). Washington, DC: American Psychological Association.

Anderson, C. A. (1997). Effects of violent movies and trait hostility on hostile feelings and aggressive thoughts. Aggressive Behavior, 23, 
161-178. doi:10.1002/(SICI)1098-2337(1997)23:3<161::AID-AB2>3.0.CO;2P

Anderson, C. A. (2010). Violent video game effects on aggression, empathy, and prosocial behavior in eastern and western countries: A meta-analytic review. Psychological Bulletin, 136, 151-173. doi:10.1037/a0018251

Anderson, C. A., Anderson, K. B., \& Deuser, W. E. (1996a). Examining an affective aggression framework: Weapon and temperature effects on aggressive thoughts, affect and attitudes. Personality and Social Psychology Bulletin, 22, 366-376. doi:10.1177/0146167296224004

Anderson, C. A., \& Bushman, B. J. (2002). Human aggression. Annual Review of Psychology, 53, 27-51. doi:10.1146/annurev.psych.53.100901.135231

Anderson, C. A., \& Carnagey, N. L. (2009). Causal effects of violent sports video games on aggression: Is it competitiveness or violent content? Journal of Experimental Social Psychology, 45, 731-739. doi:10.1016/j.jesp.2009.04.019

Baron, R. A., \& Richardson, D. R. (1994). Human aggression (2nd ed.). New York: Plenum.

Berkowitz, L. (1993). Pain and aggression: Some findings and implications. Motivation and Emotion, 17, 277-293.

doi:10.1007/BF00992223

Berkowitz, L., Corwin, R., \& Heironimus, M. (1963). Film violence and subsequent aggressive tendencies. Public Opinion Quarterly, 27, 217-229. doi: $10.1086 / 267162$

Bushman, B. J. (1995). Moderating role of trait aggressiveness in the effects of violent media on aggression. Journal of Personality and Social Psychology, 69, 950-960. doi:10.1037/0022-3514.69.5.950

Bushman, B. J. (1996). Individual difference in the extent and development of aggressive cognitive-associative networks. Personality and Social Psychology Bulletin, 22, 811-819. doi: $10.1177 / 0146167296228004$

Bushman, B. J., \& Anderson, C. A. (2001). Is it time to pull the plug on the hostile versus instrumental aggression dichotomy? Psychological Review, 108, 273-279. doi:10.1037/0033-295X.108.1.273

Bushman, B. J. (1995). Moderating role of trait aggressiveness in the effects of violent media on aggression. Journal of Personality and Social Psychology, 69, 950-960. doi:10.1037/0022-3514.69.5.950

Buss, A. H., \& Perry, M. P. (1992). The aggression questionnaire. Journal of Personality and Social Psychology, 63, 452-459. doi:10.1037/0022-3514.63.3.452

Carnagey, N. L., Anderson, C. A. (2005). The effects of reward and punishment in violent video games on aggressive affect, cognition, and behavior. Psychological Science, 16, 882-889. doi:10.1111/j.1467-9280.2005.01632.x

Centerwall, B. S. (1989). Exposure to television as a cause of violence. In G. Comstock (Ed.), Public communication and behavior (pp. 158). San Diego, CA: Academic Press.

Cross, C. P. \& Campbell, A. (2012). The effects of intimacy and target sex on direct aggression: Further evidence. Aggressive Behavior, 38, 272-280. doi:10.1002/ab.21430

Dubanoski, R. A., \& Parton, D. A. (1971). Imitative aggression in children as a function of observing a human model. Developmental Psychology, 4, 489. doi:10.1037/h0030977

Freedman, J. L. (2002). Media violence and its effect on aggression: Assessing the scientific evidence. Toronto: University of Toronto
Press. doi: $10.1037 / 0033-2909.96 .2 .227$

Freedman, J. L. (1984). Effect of television violence on aggressiveness. Psychological Bulletin, 96, 227-246.

Geen, R. G. (2001). Human aggression (2nd ed.). Oxford: Taylor \& Francis.

Hennigan, K. M. et al. (1982). Impact of the introduction of television on crime in the United States: Empirical findings and theoretical implications. Journal of Personality and Social Psychology, 42, 461477. doi:10.1037/0022-3514.42.3.461

Huesmann, L. R. (1986). Psychological processes promoting the relation between exposure tomedia violence and aggressive behavior by the viewer. Journal of Social Issues, 42, 125-139. doi:10.1111/j.1540-4560.1986.tb00246.x

Huesmann, L. R., Moise-Titus, J., Podolski, C. L., \& Eron, L. D. (2003). Longitudinal relations between children's exposure to TV violence and their aggressive and violent behavior in young adulthood: 1977-1992. Developmental Psychology, 39, 201-221. doi:10.1037/0012-1649.39.2.201

Kalnin, A. J. et al. (2011). The interacting role of media violence exposure and aggressive-disruptive behavior in adolescent brain activtion during an emotional Stroop task. Psychiatry Research, 192, 1219. doi:10.1016/j.pscychresns.2010.11.005

Katja, B., Robina, B., Menno, R. K., \& Ewald, N. (2009). Influence of aggression on information processing in the emotional Stroop task-an event-related potential study. Frontiers in Behavioral Neuroscience, 3, 28-38.

Khoury, K. M. (2012). Perpetration of aggressive behaviors against peers and teachers as predicted by student and contextual factors. Aggressive Behavior, 38, 253-262. doi:10.1002/ab.21424

Leyens, J. P., Camino, L., Parke, R. D., \& Berkowitz, L. (1975). Effects of movie violence on aggression in a field setting as a function of group dominance and cohesion. Journal of Personality and Social Psychology, 32, 346-360. doi:10.1037/0022-3514.32.2.346

Maltin, L., \& Richard W. B. $(1977,1992)$. The little rascals: The life \& times of our gang. New York: Crown Publishing/Three Rivers Press.

McDonagh, M. (2011). "Frank miller's ‘sin city"”. TV Guide. http://movies.tvguide.com/frank-millers-sin-city/137842

Messner, S. F. (1986). Television violence and violent crime: An aggregate analysis. Social Problems, 33, 218-234. doi:10.2307/800706

Paik, H., \& Comstock, G. (1994). The effects of television violence on antisocial behavior: A meta-analysis. Communication Research, 21, 516-546. doi:10.1177/009365094021004004

Smith, P., \& Waterman, M. (2005). Sex differences in processing aggression words using the emotional Stroop task. Aggressive Behavior, 31, 271-282. doi:10.1002/ab.20071

Wallace, M. T., Barry, C. T., Zeigler, H. V., \& Green, B. A. (2012). Locus of control as a contributing factor in the relation between self-perception and adolescent aggression. Aggressive Behavior, 38, 213-221. doi: $10.1002 / \mathrm{ab} .21419$

Williams, T. M. (1986). The impact of television: A natural experiment in three communities. Orlando, FL: Academic Press.

Youssef, H., Laurent, B., Michael, S., \& Bushman, B. J. (2013). The more you play, the more aggressive you become: A long-term experimental study of cumulative violent video game effects on hostile expectations and aggressive behavior. Journal of Experimental Social Psychology, 49, 224-227. doi:10.1016/j.jesp.2012.10.016 